Ciencia y Salud, Vol. III, No. 1, enero-abril, 2019 • ISSN: 2613-8816 | E-ISSN: 2613-8824

DOI: https://doi.org/10.22206/cysa.2019.v3i1.pp79-88

\title{
ADENOCARCINOMA DE PULMÓN POBREMENTE INDIFERENCIADO. A PROPÓSITO DE UN CASO
}

\author{
Poultry indiferentiated lung adenocarcinoma. A case presentation
}

\author{
Ramona Méndez Roman, ${ }^{*}$ Lissabel Altagracia Guzmán Valerio** \\ y Giovanny Masiel Severino Cruz***
}

Fecha de recibido: 3 abril 2018 • Fecha de aprobado: 6 junio 2018

Cómo citar: Méndez Roman R, Guzmán Valerio LA, Severino Cruz GM. Adenocarcinoma de pulmón pobremente indiferenciado. A propósito de un caso. cysa [Internet]. 11 abr. 2019 [citado 12 abr. 2019];1(1):79-8. Available from: https://revistas.intec.edu. do/index.php/cisa/article/view/1335

\section{Resumen}

El cáncer es una de las principales causas de muerte en el mundo. Es la neoplasia más frecuente y con mayor mortalidad en ambos sexos en los países desarrollados. Su pronóstico global es malo con una supervivencia total a los 5 años del 15\%. Los factores de riesgo para el CP son diversos, pero destacan el tabaquismo, tanto activo como pasivo; exposición a radiación por gas radón; dieta; exposición a compuestos químicos como asbestos, arsénico, cloruro de vinilo, cromato de níquel, clorometilo de éter, entre muchas otras sustancias más. El CP se considera como enfermedad centinela del tabaquismo por las siguientes razones: 1. Fumar tabaco es el factor de riesgo presente en $90 \%$ de los pacientes con CP. 2. El riesgo de enfermar o morir por $\mathrm{CP}$ en fumadores aumenta drásticamente después de los 40 años de edad. 3. Las tasas de mortalidad por CP aumentan después de los 40 años de edad, en relación directa con el consumo de tabaco. 4. Después de 10 años de abstinencia, el riesgo relativo de desarrollar CP se reduce $50 \%$ en comparación con la persistencia en el hábito. El carcinoma

\footnotetext{
* Hospital Salvador Bienvenido Gautier.

Email: Lissabel_17@hotmail.com

** Hospital Salvador Bienvenido Gautier.

Email: dramendezendocrino@hotmail.com

*** Hospital Salvador Bienvenido Gautier.

Email: masielsev@hotmail.com
}

no de células pequeñas de pulmón (CNCP) supone el 80$85 \%$ de los CP. Incluye fundamentalmente, los siguientes tipos histológicos: epidermoide, adenocarcinoma y de células grandes. A su presentación sólo el $25 \%$ son estadios localizados, y un $35 \%$ son estadios localmente avanzados (estadio III o IV). Aproximadamente el 80\% de los pacientes con CNCP presentan enfermedad metastásica en alguna de sus fases evolutivas: $30-40 \%$ al diagnóstico, $50 \%$ por recidiva de los estadios I-II y $80 \%$ por progresión o recaída de los estadios III, y su supervivencia es muy pobre. El carcinoma de células pequeñas de pulmón (CCP) constituye aproximadamente el $15-20 \%$ de las neoplasias pulmonares. Aproximadamente el 60-70\% de los pacientes tienen enfermedad diseminada en el momento del diagnóstico.

Palabras clave: Tumor; maligno; adenocarcinoma; pulmón; indiferenciado.

\section{Abstract}

Cancer is one of the leading causes of death in the world. It is the most frequent neoplasm and with the highest mortality in both sexes in developed countries. Its overall prognosis is poor with a 5-year total survival of $15 \%$. The risk factors for PC are diverse, but they emphasize smoking, both active and passive; radiation exposure by radon gas; diet; exposure to chemical compounds such as asbestos, arsenic, vinyl chloride, nickel chromate, chloromethyl 
ether, among many other substances. CP is considered as a sentinel disease of smoking for the following reasons: 1. Tobacco smoking is the risk factor present in $90 \%$ of patients with PC. 2. The risk of getting sick or dying from $\mathrm{PC}$ in smokers increases dramatically after 40 years of age.

3. CP mortality rates increase after 40 years of age, directly related to tobacco use. 4 . After 10 years of abstinence, the relative risk of developing CP is reduced by $50 \%$ compared to persistence in habit. Non-small cell lung carcinoma (CNCP) accounts for $80-85 \%$ of PC. It mainly includes the following histological types: epidermoid, adenocarcinoma and large cell types. At presentation only $25 \%$ are localized stages, and $35 \%$ are locally advanced stages (stage III or IV). Approximately $80 \%$ of patients with CNCP present metastatic disease in some of its evolutionary phases: $30-40 \%$ at diagnosis, $50 \%$ due to recurrence of stages I-II and $80 \%$ due to progression or relapse of stages III, and its Survival is very poor. Small cell lung carcinoma (PCC) constitutes approximately $15-20 \%$ of lung neoplasms. Approximately $60-70 \%$ of patients have disseminated disease at the time of diagnosis.

Keywords: Tumor; malignant; adenocarcinoma; lung; undifferentiated.

\section{Introducción}

El cáncer de pulmón (CP) es el tumor más frecuente y el que mayor mortalidad ocasiona en el mundo desarrollado. Para el 2015 ocasionó 8,8 millones de defunciones. Casi una de cada seis defunciones en el mundo se debe a esta enfermedad. ${ }^{12}$ La incidencia del CP en Espańa es de 52 casos por 100.000 habitantes, cuatro menos que la media europea, debido probablemente a la relativamente tardía adopción por la mujer del hábito tabáquico. ${ }^{7}$ Sin embargo, se espera que el CP en la mujer supere en incidencia y mortalidad al cáncer de mama. En el hombre, la incidencia y mortalidad por CP ha dejado de aumentar como resultado de la disminución del hábito tabáquico en las últimas décadas. ${ }^{9}$

El humo del tabaco es el factor de riesgo más importante para el desarrollo del CP. Los fumadores tienen un riesgo entre 15 y 25 veces mayor que los no fumadores de padecer CP. De la misma forma, la exposición pasiva al humo del tabaco incrementa el riesgo de desarrollar un CP entre un 20 y un 30\% respecto a la población no expuesta. ${ }^{1} \mathrm{El}$ riesgo está relacionado con el número de cigarrillos, la duración del hábito, la edad de inicio, la profundidad de la inhalación del humo y la cantidad de alquitrán y nicotina de los cigarrillos. El humo del tabaco contiene multitud de agentes carcinogénicos o pro-carcinogénicos que son responsables de las mutaciones de los genes que regulan el crecimiento celular. ${ }^{3}$ Dejar de fumar produce una disminución gradual del riesgo de CP. Tras 15 años de abstinencia, el riesgo de desarrollar CP se aproxima al de la población no fumadora, aunque sin alcanzarlo. ${ }^{11}$ La exposición laboral al alquitrán, hollín, arsénico, cromo y níquel $y$, sobre todo, al asbesto, incrementa el riesgo de CP, al igual que la exposición a radiaciones ionizantes, ya sean de transferencia energética lineal baja -rayos x y gamma- o alta -radon y neutrones-. Otros factores de riesgo para CP son una dieta baja en frutas y vegetales, la presencia de enfermedad obstructiva crónica y de neumoconiosis. ${ }^{14}$

La susceptibilidad a desarrollar CP depende fundamentalmente de cuatro tipos de genes: oncogenes, genes supresores tumorales, genes codificadores de enzimas convertidoras de pro-carcinogénicos en carcinogénicos y genes inhibidores de carcinogénicos. ${ }^{2}$ Desde el punto de vista histológico, se suceden los siguientes cambios: proliferación de las células basales, desarrollo de atípias nucleares y nucleolos prominentes, estratificación, metaplasia escamosa, carcinoma in situ y carcinoma invasor. ${ }^{1}$

La clasificación anatomo-patológica tiene importantes implicaciones pronósticas y terapéuticas. Existen dos grandes grupos de CP: carcinoma no microcelular y carcinoma de células pequeñas. ${ }^{3}$ Dentro del grupo carcinoma no microcelular se encuentran el epidermoide -incluyendo el escamoso-, el adenocarcinoma -incluyendo el bronquioloalveolar- el de células grandes -incluyendo el de células gigantes y el de células claras- y los mixtos, como el adenoescamoso. ${ }^{5}$ 
El CP suele ser clínicamente silente durante la mayor parte de su curso. Sin embargo, en el momento del diagnóstico, el $90 \%$ de los pacientes están sintomáticos; en el resto, el diagnóstico de CP se sospecha por hallazgos radiológicos. ${ }^{10}$

Pueden presentar tos ya sea aguda o crónica es el síntoma más frecuente, hemoptisis, disnea, fiebre, debilidad general, molestias torácicas intermitentes y mal definidas, pero cuando el tumor afecta a la pleura el dolor adquiere características pleuríticas. ${ }^{17}$

El CP se sospecha tras la aparición de una imagen radiológica compatible en un paciente habitualmente sintomático. ${ }^{19} \mathrm{El}$ método para obtener una confirmación citohistológica depende del tamaño y localización de la lesión pulmonar, de la sospecha de probables metástasis extratorácicas y de la actitud terapéutica prevista. Entre los métodos diagnósticos están la biopsia pleural por toracoscopia es el método más rentable en el estudio del derrame pleural que acompaña a un posible $\mathrm{CP}$, con una sensibilidad entre el 90 y el $100 \%$. ${ }^{3}$ Toma de muestra citohistológica mediante fibrobroncoscopia con punción-aspiración transtraqueo-bronquial, punciónaspiración transtorácica o ecográfico-endoscópica. La citología de esputo es especialmente útil en los pacientes con tumores centrales y que tienen expectoración hemoptoica, con una sensibilidad cercana al $70 \% .{ }^{16} \mathrm{La}$ fibrobroncoscopia y las técnicas cito-histológicas asociadas -broncoaspirado, cepillado, biopsia bronquial y biopsia transbronquial- ofrecen una alta rentabilidad diagnóstica, fundamentalmente cuando la lesión es central y visible endoscópicamente, con una sensibilidad cercana al 90\%. La tomografía por emisión de positrones (PET) es capaz de detectar una alta tasa metabólica tisular, por lo que puede tener cierta utilidad en la caracterización de una lesión pulmonar. La sensibilidad y especificidad de la PET en la caracterización de una lesión pulmonar como maligna es del 97 y $78 \%$, respectivamente. ${ }^{18}$
El cáncer de pulmón permanece como un desafío para la medicina, porque a pesar de los avances en técnicas diagnósticas y en recursos terapéuticos, los resultados continúan siendo magros, evidenciándose tasa baja de curaciones y pequeńo tiempo de vida posdiagnóstico. ${ }^{8} \mathrm{La}$ diseminación en el momento del diagnóstico es de $40 \%$ en los casos de cáncer de células no pequeñas y de $70 \%$ en el cáncer de células pequeñas, siendo el compromiso metastático a ganglios, hueso, médula ósea, cerebro, hígado y suprarrenal. En $10 \%$ de casos, los pacientes con neoplasia maligna pulmonar son asintomáticos. ${ }^{10}$

\section{Método}

Se realizó historia clínica de la paciente ingresada, se evaluó la misma y se confeccionó una ficha donde se recogieron los siguientes datos:

- Nombre de la paciente

- Edad, sexo, raza

- Motivo de ingreso

- Historia de la enfermedad actual

- Antecedentes patológicos

- Datos positivos al examen físico

- Resultados de los estudios complementarios

- Tratamiento indicado

\section{Presentación del caso clínico}

Paciente femenina de 68 ańos de edad, ama de casa, G9 P9, con antecedentes de sarampión, varicela y parotiditis en la infancia. En la adultez tiene antecedentes mórbidos conocidos de fumadora de 30 cigarrillos por día por 34 años (índice paquete/ año de 51), exposición al humo de la leña desde la niñez, hipertensión arterial diagnosticada hace de 22 ańos tratada con carvedilol $12.5 \mathrm{mg}$, diabetes mellitus tipo 2 diagnosticada hace 17 años tratada con insulina NPH 20 unidades en la mañana y 10 unidades en la noche, refiere hace 36 años histerectomía por sangrado uterino anormal más salpingoclasia por paridad satisfecha y hace 20 años 
se le realizó una escisión de lipoma en miembro inferior derecho, quien fue ingresada en el Hospital Salvador Bienvenido Gautier porque 22 días previos inicia cuadro clínico caracterizado por dolor en miembro inferior derecho de fuerte intensidad, de $8 / 10$ en la escala del dolor, no irradiado que no se modifica ni mejora con los cambios posturales, tratado con analgésico tipo diclofenac con el cual mejora para luego reaparecer con iguales características, acompañada de eritema, tumefacción, calor, rubor y edema; 21 días previos presenta dolor torácico, localizado en hemitorax izquierdo, tipo punzante, de fuerte intensidad de 7/10 en la escala del dolor, no irradiado, que no se modifica con los cambios posturales ni con los movimientos respiratorios, acompañada de fiebre no termometrada, sin predominio de horario, medicada con antipirético tipo acetaminofén, con el cual mejora para luego reaparecer con igual característica y disnea insidiosa y progresiva que toleraba el decúbito que 3 días previos se exacerba la disnea no tolerando el decúbito, acompañada de tos, no persistente con expectoración amarillenta, sin predominio de horario, no medicada aunado a esto paciente refiere pérdida de peso de 11 libras en 3 meses, no asociado a la ingesta.

$\mathrm{Al}$ examen físico paciente taquipneica, afebril, que luce crónicamente enferma, que se evidencia masa en región supraclavicular derecha de aproximadamente $10 \times 3 \mathrm{cms}$, fija, dura, de borde irregulares, no dolorosa a la palpación, que inició hace 2 meses pequeña con las mismas características y fue aumentando de tamaño. El tórax hiperdinámico, con retracciones intercostales y subcostales, no Harzer, no Dressler, no thrill, ápex en 5to EIC LMCI, frémito táctil ausentes en los $2 / 3$ inferior derecho y en la base del pulmón izquierdo. Pulmones hipoventilados, murmullo vesicular ausente en el $2 / 3$ inferior del pulmón derecho y disminuido en la base del pulmón izquierdo con crepitantes dispersos en el resto. En abdomen presencia de cicatriz de 10 $\mathrm{cm}$ en la línea media. El miembro inferior derecho presenta edema $3(+)$ duro, que deja fóvea a la digito presión, eritema, tumefacción, calor, rubor, doloroso a la palpación y movilización con pulso femoral adecuado pero poplíteo y tibial disminuido.

Se ingresa con el diagnóstico de Neumonía adquirida en comunidad, Enfermedad pulmonar obstructiva crónica exacerbada probable y Cáncer de pulmón a descartar. La toracocentesis se visualiza líquido pleural hemático que reporta exudado a expensa de linfocitos. Y los gases arteriales reportaron acidosis respiratoria con alcalosis metabólica concomitante. Paciente a los 4 días de ingreso empeora cuadro de mecánica ventilatoria presentando desaturación con necesidad de oxigenoterapia por cánula y marcada disnea. Se le realiza $\mathrm{Rx}$ tórax nueva que reporta neumonía bilateral y derrame pleural bilateral siendo más predominante el pulmón izquierdo y cisuritis. Se le realiza otra toracocentesis con líquido pleural hemático siendo el exudado a expensa de neutrófilos por lo que se inicia antibioterapia con meropenem y vancomicina. Se agrega inhaladores tipo LABA, SAMA y esteroides inhalados, así como esquema de prednisona presentando mejoría clínica paulatinamente.

Paciente a los 9 dias de ingreso todavía presenta disnea aunque en mejoría, por lo que se realiza $\mathrm{Rx}$ totax PA que reporta derrame pleural bilateral siendo el izquierdo masivo por lo que se realiza una biopsia pleural y tocarocentesis terapéutica drenando $2500 \mathrm{cc}$ de liquido pleural hemático realizándole estudio al líquido pleural reportando exudado a expensa de linfocitos. Se indica lisozima $250 \mathrm{mg}$ c/ 12 horas e inspirometria incentiva cada 2 horas por 20 minutos.

Se realiza Doppler de miembros inferiores que reporta trombo en safena interna e insuficiencia venosa superficial y profunda por lo que se inició anticoagulación con rivaroxabán y medias comprensivas. Se le realiza tac de cuello que reporta bocio multinodular y engrosamiento de partes blandas condroesternal derecho asociada a enfermedad 
inflamatoria. Y la TAC de tórax que reporta infiltrados bilaterales, derrame pleural bilateral y masa ocupante de espacio

\section{Estudios y laboratorios de extensión}

Dentro de lo estudios de laboratorio se le realizó un hemograma con GB: 25.3 NEUT 73.1 LINF 8.1 HB 10.1 HCT 29.9 PLT VCM 75 HCM 25.3 CHCM 33.7.

El perfil férrico reflejó anemia asociado a enfermedades crónicas y presentó una vitamina B12 en $1117 \mathrm{pg} / \mathrm{ml}$. Albúmina en 2.6, proteínas totales 6.32, sodio 137 , potasio 2.8 y cloro 96 , eritrosedimentación y PCR elevada, procalcitonina en 0.82 . Se le realiza perfil tiroideo dentro de límites normales y virales con resultados negativos.

Cultivos de líquido de pleural negativo pero hemocultivo y urocultivo reportó MRSA. Se realiza cultivo de esputo y baciloscopia con resultados negativos así como pro Bnp en 728. Se realiza hisopado de axilas, áreas inguinales y fosas nasales que alojo MRSA. Se realiza ecocardiograma sin hallazgos relevantes.

Se le realiza $\mathrm{Rx}$ Tórax que refleja neumonía bilateral a predominio izquierdo, efusión pleural bilateral de predominio izquierdo.

La sonografía tiroidea que reporta bocio multinodular.

Se realiza Doppler de miembros inferiores que reporta trombo en safena interna e insuficiencia venosa superficial y profunda.

\section{Marcadores tumorales}

- CA 125 en 63.00 U/ML

- Alfa feto proteína en $0.84 \mathrm{UI} / \mathrm{ML}$

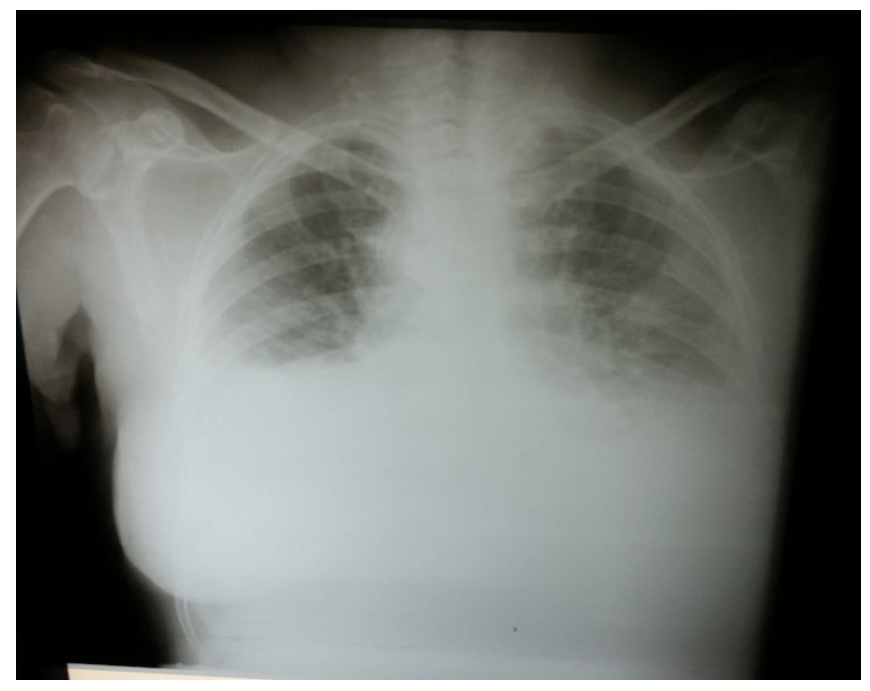

Ilustración $1 \mathrm{Rx}$ Torax PA con hallazgos de derrame pleural bilateral e infiltrado intersticial bilateral

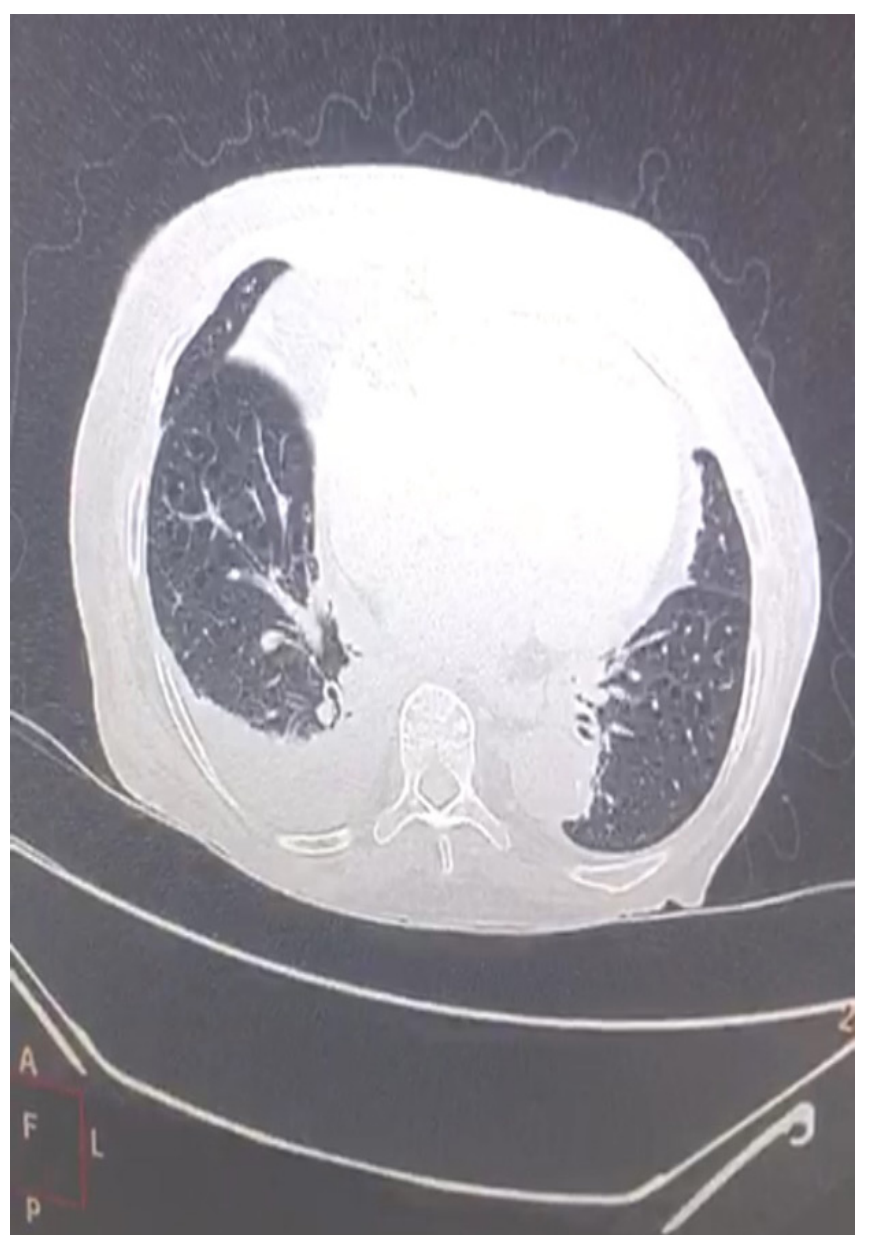




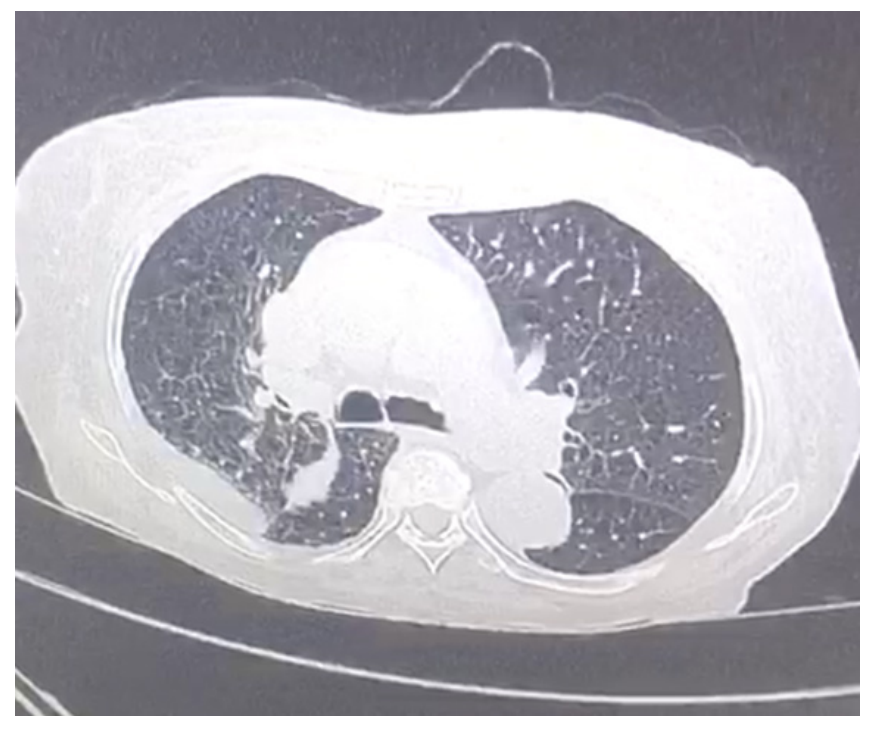

TAC Torax de la paciente donde se visualiza masa ocupante de espacio en lóbulo medio de campo pulmonar derecho y derrame pleural bilateral

\section{Discusión}

El cáncer de pulmón $(\mathrm{CP})$ es el tumor más frecuente y el que mayor mortalidad ocasiona en el mundo desarrollado. El humo del tabaco es el factor de riesgo más importante para el desarrollo del CP. ${ }^{7}$ Los fumadores tienen un riesgo entre 15 y 25 veces mayor que los no fumadores de padecer CP. De la misma forma, la exposición pasiva al humo del tabaco incrementa el riesgo de desarrollar un CP entre un 20 y un $30 \%$ respecto a la población no expuesta. El riesgo está relacionado con el número de cigarrillos, la duración del hábito, la edad de inicio, la profundidad de la inhalación del humo y la cantidad de alquitrán y nicotina de los cigarrillos. ${ }^{9}$

La exposición laboral al alquitrán, hollín, arsénico, cromo y níquel y, sobre todo, al asbesto, incrementa el riesgo de $\mathrm{CP}$, al igual que la exposición a radiaciones ionizantes, ya sean de transferencia energética lineal baja -rayos x y gamma- o alta -radon y neutrones-. Otros factores de riesgo para CP son una dieta baja en frutas y vegetales, la presencia de enfermedad obstructiva crónica y de neumoconiosis. $^{5}$
La clasificación anatomo-patológica tiene importantes implicaciones pronósticas y terapéuticas. Existen dos grandes grupos de CP: carcinoma no microcelular y carcinoma de células pequeñas. ${ }^{1}$ Dentro del grupo carcinoma no microcelular se encuentran el epidermoide -incluyendo el escamoso-, el adenocarcinoma -incluyendo el bronquioloalveolar- el de células grandes -incluyendo el de células gigantes y el de células claras- y los mixtos, como el adenoescamoso. ${ }^{6}$ La mayoría de los adenocarcinomas se originan periféricamente, con frecuencia sobre cicatrices o en regiones con fibrosis intersticial; al microscopio óptico muestran formaciones glandulares, estructura papilar o producción de mucina; en el análisis inmunohistoquímico expresan citoqueratinas de bajo peso molecular, antígeno carcinoembrionario y antígeno de membrana celular; el carcinoma bronquiolo-alveolar es un subtipo de adenocarcinoma con un patrón de crecimiento puramente bronquioloalveolar, sin invasión del estroma, vasos ni pleura; es el tumor de mejor pronóstico, debido a su alto grado de diferenciación. ${ }^{9}$

El carcinoma pulmonar de células no pequeñas es el subtipo más frecuente en la población, representa el $75 \%$ de todos los tumores pulmonares. 2, 3 Tienen pronóstico sombrío (solo el $16 \%$ sobrevive a los cinco años) por la baja efectividad de los tratamientos y desarrollo de resistencia tumoral intrínseca y adquirida. Posee tres tipos histológicos: carcinoma escamoso de células grandes y adenocarcinoma. ${ }^{2}$ Este último es la forma más frecuente de $\mathrm{CP}$ entre las mujeres y entre personas que no fuman; según varios estudios también entre los hombres. Un posible factor reside en mayor cantidad de mujeres que fuman y mayor vulnerabilidad frente a los carcinógenos del tabaco. Crece con mayor lentitud que los carcinomas epidermoides pero tienden a metastatizar antes y de manera más amplia. ${ }^{4}$

Se piensa que los factores ambientales contribuyen más en la patogenia que los factores genéticos. ${ }^{4}$ Aunque el CP está de manera clara relacionado 
con el hábito de fumar cigarrillos (el $87 \%$ aparece en fumadores o en personas que han dejado de fumar poco tiempo atrás), la mortalidad ha resultado cuatro veces mayor entre familiares no fumadores de pacientes con CP que entre familiares no fumadores de controles. ${ }^{5}$ Un fumador medio de cigarrillos tiene un riesgo diez veces mayor de contraer un $\mathrm{CP}$ y en los fumadores empedernidos (más de 40 cigarrillos al día durante varios años) esta cifra sube hasta sesenta veces. ${ }^{4}$ Los adenocarcinomas incluidos los carcinomas bronquiolo alveolares tienen menos relación con el tabaco (más del 75 $\%$ corresponde a fumadores) que los carcinomas epidermoides (más del $98 \%$ son fumadores). ${ }^{4}$

El CP suele ser clínicamente silente durante la mayor parte de su curso. Sin embargo, en el momento del diagnóstico, el $90 \%$ de los pacientes están sintomáticos; en el resto, el diagnóstico de $\mathrm{CP}$ se sospecha por hallazgos radiológicos. Los síntomas y signos derivan del crecimiento tumoral local, de la obstrucción o invasión de las estructuras adyacentes, de la afectación de las estaciones ganglionares regionales, de la diseminación hematógena extratorácica y de los efectos ocasionados por substancias biológicas producidas por el tumor -síndromes paraneoplásicos. ${ }^{9}$

La tos de nueva presentación o el cambio en la naturaleza de la tos crónica es el síntoma más frecuente, hemoptisis, ya sea franca o, más frecuentemente, en forma de expectoración hemoptoica recurrente, suele aparecer cuando se ulcera la mucosa bronquial. ${ }^{12}$ La disnea es también un síntoma frecuente, generalmente asociada a un incremento de la expectoración y de la tos. La mitad de los pacientes manifiestan ciertas molestias torácicas intermitentes y mal definidas, pero cuando el tumor afecta a la pleura el dolor adquiere características pleuríticas. ${ }^{14}$

El manejo diagnóstico y terapéutico de estos pacientes es complejo y la estadificación del mediastino es esencial para definir tratamiento oncoespecífico y evitar cirugías innecesarias. ${ }^{17}$ Para detectar el compromiso neoplásico de los ganglios mediastinales se cuenta con diferentes métodos de imágenes o invasivos como la TAC, tomografía por emisión de positrones con 18F- fluorodeoxiglucosa, fibrobroncoscopía con punción transbronquial, ultrasonografía transbronquial, mediastinoscopia y videotoracoscopia. ${ }^{16}$

El CP se sospecha tras la aparición de una imagen radiológica compatible en un paciente habitualmente sintomático. El método para obtener una confirmación citohistológica depende del tamaño y localización de la lesión pulmonar, de la sospecha de probables metástasis extratorácicas y de la actitud terapéutica prevista. Si el tumor primario se acompaña de un derrame pleural, la vía más eficiente es su estudio; el estudio citológico del líquido pleural tiene mayor sensibilidad que la biopsia pleural ciega; no obstante, la biopsia pleural por toracoscopia es el método más rentable en el estudio del derrame pleural que acompaña a un posible CP, con una sensibilidad entre el 90 y el $100 \%{ }^{2}$ Si las técnicas de imagen ponen de manifiesto una afectación mediastínica extensa, la toma de muestra citohistológica mediante fibrobroncoscopia con punción-aspiración transtraqueo-bronquial, punciónaspiración transtorácica o ecográfico-endoscópica, pueden establecer el diagnóstico y la estadificación mediastínica. ${ }^{6}$ Cuando la lesión se manifiesta como un nódulo pulmonar solitario periférico, sin datos que hagan sospechar estadio avanzado de la enfermedad, en un paciente con alto riesgo epidemiológico y clínico para $\mathrm{CP}$, un riesgo quirúrgico aceptable y una actitud positiva para la cirugía, la biopsia por excisión mediante toracoscopia y la subsiguiente lobectomía (si se confirma el diagnóstico) es, sin duda, la conducta más eficiente. ${ }^{8}$ Para las restantes presentaciones existe una gama de pruebas diagnósticas que oscilan desde las absolutamente incruentas -como la citología de esputo- a la exploración quirúrgica mediante toracoscopia o toracotomía. ${ }^{11}$ 
La citología de esputo es especialmente útil en los pacientes con tumores centrales y que tienen expectoración hemoptoica, con una sensibilidad cercana al 70\%. La fibrobroncoscopia y las técnicas cito-histológicas asociadas -broncoaspirado, cepillado, biopsia bronquial y biopsia transbronquialofrecen una alta rentabilidad diagnóstica, fundamentalmente cuando la lesión es central y visible endoscópicamente, con una sensibilidad cercana al $90 \%$. En las lesiones periféricas, la rentabilidad diagnóstica de la fibrobroncoscopia depende del tamaño del tumor, de la localización, de la existencia de afectación bronquial en la tomografía computarizada (TC), de si está guiada por fluoroscopia y del número de muestras biópsicas que se tomen, con una sensibilidad próxima al $70 \%{ }^{8}$

La punción-aspiración transtorácica en las lesiones periféricas alcanza una sensibilidad global del 90\%. La rentabilidad es mayor cuando la punción está guiada por TC que por fluoroscopía. Sin embargo, dado el relativo alto porcentaje de falsos negativos, la punción-aspiración transtorácica no es útil para descartar un cáncer; por ello, ahondando en lo anteriormente expuesto, esta prueba no está justificada en el diagnóstico de una lesión sospechosa de CP, en un estadio aparentemente inicial, y en un paciente buen candidato para la cirugía. ${ }^{10}$

La tomografía por emisión de positrones (PET) es capaz de detectar una alta tasa metabólica tisular, por lo que puede tener cierta utilidad en la caracterización de una lesión pulmonar. La sensibilidad y especificidad de la PET en la caracterización de una lesión pulmonar como maligna es del 97 y 78\%, respectivamente. Los resultados falsos negativos pueden deberse al tamaño de las lesiones. ${ }^{19}$

La expectativa de vida de los pacientes con carcinoma broncogénico es pobre. Vázquez Sequeiros, et al, opinan que cuando la enfermedad es resecable en estadio I los pacientes alcanzan una supervivencia a los cinco años del $80 \%$ pero sobrevida breve cuando hay afectación metastásica, en la que no recomiendan la resección quirúrgica aislada como terapia de primera línea, mientras que Lima Guerra A, et al, en una serie de 51 pacientes operados lograron supervivencia a los cinco ańos de 57, $1 \%$, con una media de 47,8 meses. $^{3}$

Entre las opciones actuales de tratamiento del CPCNP se incluyen quimioterapia, cirugía, radioterapia y enfoques inmunológicos en dependencia del estadio del tumor. Estos últimos son interesantes debido al potencial de actividad sin las toxicidades de la quimioterapia convencional, que da lugar a que muchos pacientes no reciban este tratamiento incluso en el marco de terapia de primera línea. ${ }^{2}$ La terapia biológica es el estándar de primera línea en el CPCNP, entre la que destacan los inhibidores de tirosina quinasa, como el erlotinib. Los estudios OPTIMAL ${ }^{(4)}$ (asiático) y EURTAC ${ }^{(5)}$ (europeo), ambos estudios de fase III, demostraron la superioridad de las terapias moleculares sobre la quimioterapia clásica. ${ }^{1}$ Como cabe suponer, para la instauración de esta terapia biológica se necesita evaluar el estado mutacional del EFGR. El estudio PIONEER, primer estudio prospectivo que confirmó altas frecuencias de mutaciones del EFGR $(51,4 \%)$ en pacientes con adenocarcinoma, demostró que las mutaciones del EGFR se correlacionaron significativamente con el sexo femenino $(61,1 \%)$ y con no haber fumado $(60,7 \%$, disminuyendo conforme aumentaba el índice paquete/ año). ${ }^{3}$

En este paciente el método diagnóstico fue por biopsia pleural con aguja. La misma se negaba a la fibrobroncoscopia y biopsia de masa de cuello.

\section{Resultados}

La biopsia pleural reporta adenocarcinoma de pulmón pobremente indiferenciado por lo que se envía paciente a oncología. 


\section{Bibliografía}

1. Beckles MA, Spiro SG, Colice GL, Rudd RM. Initial evaluation of the patient with lung cancer: symptoms, signs, laboratory tests, and paraneoplastic syndromes. Chest 2003; 123: 97S-104S.

2. Campos Parra AD, Cruz Risco G, Arrieta O. Personalización del tratamiento del cáncer de pulmón de células no pequeñas. Rev Invest Clin [Internet]. Jul- Ago 2012 [citado 28 Ene 2016];64(4):[aprox. 8 p.].

3. Lima Guerra A, Gassiot Nuño C, Ramos Quevedo A, Rodríguez Vázquez JC, Cabanes Varona L, Morales Sánchez L, et al. Conducta diagnóstica y pronóstico en pacientes con carcinoma pulmonar de células no pequeñas en estadios quirúrgicos. Rev Cubana Med [Internet]. 2012 [citado 28 Ene 2016];51(1):[aprox. 12 p.].

4. Husain AN. Pulmón. En: Kumar V, Abbas AK, Fausto N, Aster JC, editores. Robbins y Cotran. Patología estructural y funcional. 8 ed. Barcelona: Elsevier; 2010. p. 677- 738.

5. Stricker TP, Kumar V. Neoplasias. En: Kumar V, Abbas AK, Fausto N, Aster JC, editores. Robbins y Cotran. Patología estructural y funcional. 8 ed. Barcelona: Elsevier; 2010. p. 259-330.

6. Schreiber G, McCrory DC. Performance characteristics of different modalities for diagnosis of suspected lung cancer: summary of published evidence. Chest 2003; 123: 115S-128S.

7. Mountain CF. Revisions in the International System for Staging Lung Cancer. Chest 1997; 111: 1710-7.

8. Toloza EM, Harpole L, McCrory DC. Noninvasive staging of non-small cell lung cancer: a review of the current evidence. Chest 2003; 123: 137S-146S.
9. Detterbeck FC, Falen S, Rivera MP, Halle JS, Socinski MA. Seeking a home for a PET, part 2: Defining the appropriate place for positron emission tomography imaging in the staging of patients with suspected lung cancer. Chest 2004; 125: 2300-8.

10. Gupta NC, Rogers JS, Graeber GM, Gregory JL, Waheed U, Mullet D, Atkins M. Clinical role of F-18 fluorodeoxyglucose positron emission tomography imaging in patients with lung cancer and suspected malignant pleural effusion. Chest 2002; 122: 1918-24.

11. Toloza EM, Harpole L, Detterbeck F, McCrory DC. Invasive staging of non-small cell lung cancer: a review of the current evidence. Chest 2003; 123: 157S-166S.

12. Herth F, Becker HD. New aspects in early detection and local staging of early lung cancer. Lung Cancer 2001; 34: S7-11.

13. Ginsberg RJ, Rice TW, Goldberg M, Waters PF, Schmocker BJ. Extended cervical mediastinoscopy. A single staging procedure for bronchogenic carcinoma of the left upper lobe. J Thorac Cardiovasc Surg 1987; 94: 673-8.

14. Silvestri GA, Tanoue LT, Margolis ML, Barker J, Detterbeck F; American College of Chest Physicians. The noninvasive staging of non-small cell lung cancer: the guidelines. Chest 2003; 123: 147S-156S.

15. Salvatierra A, Baamonde C, Llamas JM, Cruz F, Lopez-Pujol J. Extrathoracic staging of bronchogenic carcinoma. Chest 1990; 97: 1052-8.

16. Ferrigno D, Buccheri G. Cranial computed tomography as a part of the initial staging procedures for patients with non-small-cell lung cancer. Chest 1994; 106: 1025-9. 
17. Earnest F 4th, Ryu JH, Miller GM, Luetmer $\mathrm{PH}$, Forstrom LA, Burnett OL, et al. Suspected non-small cell lung cancer: incidence of occult brain and skeletal metastases and effectiveness of imaging for detection-pilot study. Radiology 1999; 211: 137-45.

18. Silvestri GA, Littenberg B, Colice GL. The clinical evaluation for detecting metastatic lung cancer. A metaanalysis. Am J Respir Crit Care Med 1995; 152: 225-30.
19. Sharples LD, Jackson C, Wheaton E, Griffith G, Annema JT, Dooms C, et al. Clinical effectiveness and cost- effectiveness of endobronchial and endoscopic ultrasound relative to surgical staging in potentially resectable lung cancer: Results from de ASTER randomized controlled trial. Health Technol Assess. 2012;16:1-75 